\title{
Repeated ultrasound guided local infiltration of methotrexate in persistent gestational trophoblastic disease with myometrial invasion: case series and review of literature
}

\author{
Tamer H. Said ${ }^{1 *}$, Yasser Elkerm ${ }^{2}$
}

\author{
${ }^{1}$ Department of Obstetrics and Gynecology Faculty of Medicine, Alexandria University, Alexandria, Egypt \\ ${ }^{2}$ Department of Chemotherapy and Radiotherapy, Faculty of Medicine, Alexandria University, Alexandria, Egypt
}

Received: 08 January 2021

Revised: 25 March 2021

Accepted: 31 March 2021

\section{*Correspondence:}

Dr. Tamer H. Said,

E-mail: tamer.said10@alexmed.edu.eg

Copyright: (C) the author(s), publisher and licensee Medip Academy. This is an open-access article distributed under the terms of the Creative Commons Attribution Non-Commercial License, which permits unrestricted non-commercial use, distribution, and reproduction in any medium, provided the original work is properly cited.

\begin{abstract}
Gestational trophoblastic disease is a group of rare tumors that involve abnormal growth of cells inside a woman's uterus. An invasive mole is a hydatidiform mole that has grown into the muscle layer of the uterus. Invasive vesicular moles can develop from either partial or complete moles, but complete moles become invasive much more often than do partial moles. Invasive moles develop in a little less than $20 \%$ of women who have had a complete mole evacuated. Treatment of invasive mole is classically by giving systemic chemotherapy. Objectives of current study were to evaluate the effect of repeated local methotrexate injection in treatment of invasive mole. Cases with invasive mole assigned for local injection of $50 \mathrm{mg}$ methotrexate in $10 \mathrm{~cm}$ normal saline using local injection in the myometrium under transvaginal ultrasound guidance. Follow up weekly till negative results are obtained. All cases showed rapid decrease of the level of b-hCG level after local injection and showed negative hormone results within 6 weeks after injection. Local methotrexate intra-myometrial local injection therapy has successful results in cases with persistent invasive hydatidiform mole and should be tried before referring them for systemic therapy.
\end{abstract}

Keywords: Gestational trophoblastic disease, Methotrexate, Invasive mole

\section{INTRODUCTION}

Gestational trophoblastic disease (GTD) is a group of uncommon conditions associated with pregnancy. Histologically, it includes the premalignant partial mole (PHM) and complete hydatidiform mole (CHM), as well as the malignant invasive mole, choriocarcinoma, epithelioid trophoblastic tumor (ETT) and placental site trophoblastic tumor (PSTT). The malignant forms can arise after any type of pregnancy and are collectively known as The GTD spectrum or gestational trophoblastic neoplasia $(\mathrm{GTN}) .{ }^{1}$ The placental hormone b-hCG is an ideal hormone for prognosis and follow up of GTD. A plateaued or rising hCG level enables the early detection of progression of $\mathrm{CHM}$ and $\mathrm{PHM}$ to GTN that occurs in $15 \%-20 \%$, and $0.5 \%-5 \%$ of cases, respectively. ${ }^{2}$ Approximately $10-17 \%$ of hydatidiform moles could result in invasive mole and about $15 \%$ of these will metastasize to the vagina or lungs. Invasive mole is most often diagnosed clinically rather than pathologically based on persistent hCG elevation after molar evacuation or by USG showing myometrial invasion or lesion and is frequently treated with chemotherapy without a histopathologic diagnosis. ${ }^{3}$

Current case series evaluates effect of repeated ultrasound guided local infiltration of methotrexate in cases of persistent gestational trophoblastic disease with myometrial invasion. 


\section{CASE SERIES}

In the period between June 2016 to October 2020, eleven cases of invasive gestational trophoblastic disease (invasive vesicular mole) were referred and all of them were in reproductive age group and wished to preserve their fertility. FIGO criteria for diagnosis of post-molar gestational trophoblastic neoplasia was used for diagnosis and all our series were confirmed to have invasive mole. ${ }^{4}$ All cases had neither distant metastasis to the lung nor local metastasis to the vagina. Formal abdominal USG to exclude liver metastasis and chest X-ray to exclude lung metastasis were done for all patients. Complete history about the details of the last abortion and number of dilatation and curettage performed and any chemotherapeutic agent that was used for treatment were the main points in history relevant to our study.

Complete general and local gynecological examinations were done. Complete blood count, liver enzymes, kidney functions, b-hCG level, coagulation profile, urine analysis and TSH were requested for every patient. USG was done both trans-abdominal and trans-vaginal to exclude any liver metastasis and to document vesicular ultrasonographic pattern with high vascularity and low resistance flow and consisting of multiples echoes (holes).

All cases were found to be of low risk GTN (WHO risk score 0-4). ${ }^{5}$ As all cases had already received intramuscular methotrexate injections from 2 to 5 times before their presentation to our center using different protocols so, counseling of the patient about the treatment options and alternatives they had was done and clarification of the effect of the chemotherapy on their fertility was stressed upon. Consultation of chemotherapy consultant for every patient was done to clarify the procedure and resolving any concern about the local methotrexate injection. Local methotrexate injection of $50 \mathrm{mg}$ diluted in $20 \mathrm{ml}$ saline, we used oocytes aspiration needle and the patient was sedated by IV diprivan (propofol) and isoflurane mask. Patient had been given 2 amp of kapron ${ }^{\circledR}$ infusion and $1 \mathrm{gm}$ claforan ${ }^{\circledR}$ (cefotaxime sodium) and any uterotonic drugs during or after injection were not used and no analgesics were needed.

The follow up of the patients was done on weekly basis for complete blood count, b-hCG level and USG and if the b-hCG decreased weekly case was only observed and followed up. If the b-hCG became a plateau or increased, a second session of local methotrexate injection was done and follow up as before till the b-hCG became less than 4 more than 4 consecutive weeks then weekly follow up was done then monthly thereafter for a year. Observed data were fed to the computer and analyzed using IBM SPSS software package version 20.0. (Armonk, NY: IBM Corp). The Kolmogorov- Smirnov was used to verify the normality of distribution of variables, Friedman test for abnormally distributed quantitative variables, to compare between more than two periods or stages and Post Hoc test (Dunn's) for pairwise comparisons. Significance of the obtained results was judged at the $5 \%$ level.

\section{Case 1}

A 22 year old lady G1P0+1 presented with abnormal uterine bleeding and high level of b-hCG with history of recent abortion. She had history of dilatation and curettage twice, the first was 2 months and the second surgery was 1 month before her visit to our centre and she had a diagnosis of partial vesicular mole. Abdominal and pelvic examinations were normal. USG evaluation revealed heterogenous hypo and hyperechoic mass in the subendometrial part measuring $2.1 \times 1.9 \times 1.5 \mathrm{~cm}$ with high vascularity as shown by color and power doppler study with low resistance flow, RI 0.37 giving picture of invasive mole, Thin endometrium was noted, both ovaries could be separately identified and were normal in size and echo pattern. Her BMI was $26.5 \mathrm{~kg} / \mathrm{m} 2$. She has medical history of bronchial asthma and on treatment only during her attacks. Her beta hCG was 200.000 $\mathrm{mIU} / \mathrm{ml}$ in the first visit and she received $50 \mathrm{mg}$ methotrexate IM injection and her hormone level became $31000,3000,9900,18859,27680 \mathrm{mIU} / \mathrm{ml}$, then one more shot of methotrexate $50 \mathrm{mg}$ the beta became 10470 $\mathrm{mIU} / \mathrm{ml}$ then one week later received her third shot of methotrexate and her beta hCG became $2900 \mathrm{mIU} / \mathrm{ml}$ then the chemotherapy consultant added 2 more shots of methotrexate and the beta hCG became $1435 \mathrm{mIU} / \mathrm{ml}$. She was referred to chemotherapy department and she received $65 \mathrm{mg}$ methotrexate on $250 \mathrm{ml}$ on day $1,3,5,7$ and Calcium leucovorin on days 2,4,6,8 then hCG level evaluation was done and found to be 571, 472, 438, 613 $\mathrm{mIU} / \mathrm{ml}$ consecutively with weekly measurements. Local methotrexate injection was suggested after consultation of the chemotherapy consultant and before giving the EMACO therapy (etoposide, methotrexate, actinomycin D, cyclophosphamide, vincristine chemotherapy) of invasive mole. $50 \mathrm{mg}$ diluted by $5 \mathrm{ml}$ saline was recommended to be given intralesional by transvaginal ultrasound guided. Complete investigations, bleeding and coagulation profile were done and confirmed to be normal. Patient received $\mathrm{Ab}$ and kapron amp and dicynone amp by IV infusion before local methotrexate injection.

A trial of aspiration of fluid from the lesion showed dark blood then injection was done and trial to disperse the drug in all parts of the lesion slowly. The local injections was repeated once more and follow up by USG showed regression of the high vascular lesion and decrease in size to became $0.9 \times 0.7 \times 0.5 \mathrm{~cm}$ and very thin endometrium and quiet ovaries and pelvic congestion. Beta hCG was done after 1 week and dropped from $129 \mathrm{mIU} / \mathrm{ml}$ to 14 , $6.17,7.9 \mathrm{mIU} / \mathrm{ml}$ with weekly interval. It was followed up weekly and persistent below 5 and we added OCP for 1 year. She got pregnant after 1 year and 3 months later by repeated ovulation induction and intrauterine insemination and had uneventful pregnancy. 


\section{Case 2}

The second case was 33 year old lady G2P1+1 with history of missed abortion and she had 3 dilatation and curettage surgeries in the month before her visit and still had continuous spotting. She and her husband were cousins. Her BMI was $30.2 \mathrm{~kg} / \mathrm{m} 2$ and her B-hCG was $4000 \mathrm{mIU} / \mathrm{ml}$. USG showed large interstitial mass in the myometrium to the left side $3 \times 2.3 \times 2 \mathrm{~cm}$ with low resistance flow, both ovaries were seen normal. Systemic injection of $50 \mathrm{mg}$ methotrexate was started and she received 3 shots with weekly interval and her b-hCG dropped from 4000 to $150 \mathrm{mIU} / \mathrm{ml}$ with persistent level over weeks. Counselling of the patient about local injection of methotrexate was done. The same procedure was done as the first patient except we did not aspirate any fluid or blood before injection as it is endless but we tried to cover the whole lesion with the diluted drug. After 1 week B-hCG dropped from 150 to 28 and the local injection was repeated 2 more times and b-hCG decreased slowly over weeks to normal levels after 5 weeks from the first injection. USG evaluation showed regression of the vascular lesion and white deposition and decreased echolucent areas had been noted. The abnormal vaginal bleeding stopped. Five months later, the site of the fibrosed mass was normal with mild myometrial hyperechoic remnant.

\section{Case 3}

The third case was 23 year old G0P0 and her BMI was 23 $\mathrm{kg} / \mathrm{m} 2$ and she has medical history of mild bronchial asthma, chronic anaemia, small pituitary microadenoma (prolactinoma) and was on antiprolactin treatment weekly, hepatitis $\mathrm{C}$ virus infection and was treated by (sovaldi)® and she was allergic to penicillin. She was diagnosed to have polycystic ovarian disease and endometriosis and had unilateral chocolate cyst $3 \mathrm{~cm}$. She was assigned to do laparoscopy as a treatment of endometriosis and she got pregnant 5 months later. Her pregnancy showed 2 sacs one of them is low-positioned in the cavity and had no yolk sac and the second one was irregular and normally positioned in the cavity. Two weeks later no pulsation was seen and she was diagnosed as missed abortion. She refused medical induction of abortion and underwent dilatation and curettage twice and came after it complained of persistent vaginal bleeding and persistent high b-hCG. USG examination showed bulky uterus and very thin endometrial interface and unilateral ovarian cyst $3 \mathrm{~cm}$ and heterogenous echolucent and echogenic mass in the myometrium was seen $2.5 \times 1.9 \times 0.8 \mathrm{~cm}$ with very high vascular flow and low resistance. In the beginning of examination an arteriovenous malformation was suspected but with result of high b-hCG a diagnosis of persistent mole was reached. She received 2 intramuscular shots of $50 \mathrm{mg}$ methotrexate and b-hCG decreased from 1150 to 128 $\mathrm{mIU} / \mathrm{ml}$. She had single local injection of methotrexate $50 \mathrm{mg}$ and the beta found to be 13 after 1 week then below 4 throughout all the weekly examinations thereafter. She received OCP for 1 year with folic acid supplementation. She got pregnant with simple induction of ovulation and had a normal baby after 2 year and 4 months from the local injection.

The demographic, laboratory and treatment details of the last 8 cases were documented, tabulated and analyzed in (Table 1) and the comparison between different cases regarding the level of b-hCG level in (Table 2). The graph in (Figure 1) showed the changes in level of b-hCG over the period of observation. No major intraoperative or postoperative complications were noted except a case of mild allergic reaction after injection and a case of mild lower abdominal pain and both were treated conservatively. All patients were discharged after 6 hours after local injection.

Table 1: Distribution of the studied cases according to different parameters $(n=11)$.

\begin{tabular}{|ll|}
\hline Parameters & N $(\%)$ \\
\hline Age (years) & \\
\hline Mean \pm SD & $28.2 \pm 4.4$ \\
\hline Median (range) & $28(22-36)$ \\
\hline Parity & $6(54.5)$ \\
\hline 0 & $4(36.4)$ \\
\hline 1 & $1(9.1)$ \\
\hline 2 & $0.55 \pm 0.69$ \\
\hline Mean \pm SD & $0(0-2)$ \\
\hline Median (range) & \\
\hline BMI & $26.6 \pm 4.4$ \\
\hline Mean \pm SD & $26.5(21-33)$ \\
\hline Median (range) & $5(45.5)$ \\
\hline Number of local methotrexate injections \\
\hline 1 & $6(54.5)$ \\
\hline 2 & $1.6 \pm 0.52$ \\
\hline Mean $\pm S D$ & $2(1-2)$ \\
\hline Median (range) & $3.2 \pm 0.87$ \\
\hline Number of general IM injections & $3(2-5)$ \\
\hline Mean $\pm S D$ & $2(18.2)$ \\
\hline Median (range) & $8(72.7)$ \\
\hline Number of D and C done & $1(9.1)$ \\
\hline 1 & $1.9 \pm 0.54$ \\
\hline 2 & $2(1-3)$ \\
\hline 3 & \\
\hline Mean $\pm S D$ & \\
\hline Median (range) & \\
\hline & \\
\hline & \\
\hline
\end{tabular}

\section{DISCUSSION}

Gestational trophoblastic disease (GTD) is a heterogeneous group of disorders characterized by disordered proliferation of trophoblastic tissue that originates from placental tissues in women of childbearing period. Since GTD and its malignant sequel gestational trophoblastic neoplasia (GTN) are very uncommon diseases, little evidence is available from randomized controlled trials on optimal treatment and 
follow-up protocols. Treatment protocols vary in different jurisdictions within the same country. ${ }^{5}$

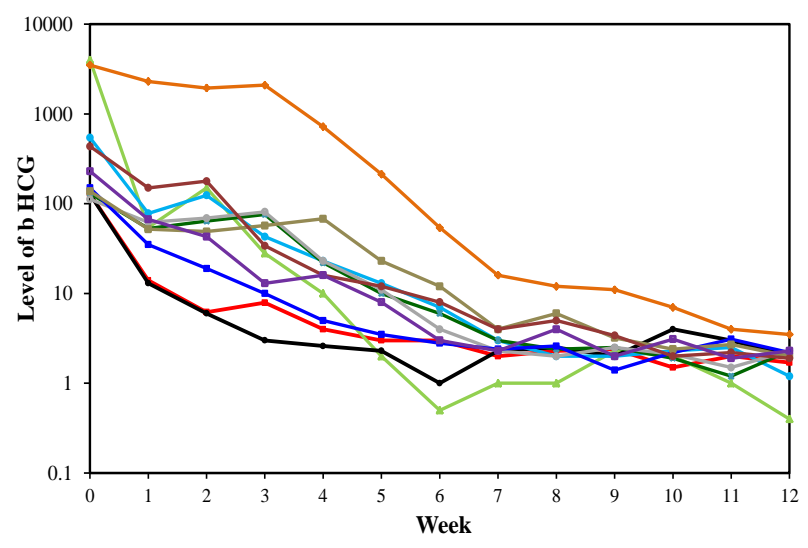

Figure 1: Comparison between the different studied periods according to level of b HCG $(n=11)$.

Table 2: Comparison between the different studied periods according to level of b HCG $(n=11)$.

\begin{tabular}{|llll|}
\hline $\begin{array}{l}\text { Duration } \\
\text { (weeks) }\end{array}$ & $\begin{array}{l}\text { Median } \\
\text { (range) }\end{array}$ & Mean \pm SD. & p value \\
\hline $\begin{array}{l}\text { Before } \\
\text { local MTR }\end{array}$ & $\begin{array}{l}150 \\
(112-4000)\end{array}$ & $863.4 \pm 1438.5$ & - \\
\hline After 1 & $\begin{array}{l}54.50 \\
(13-2300)\end{array}$ & $261.7 \pm 677$ & 0.274 \\
\hline After 2 & $64(6-1943)$ & $241 \pm 567.4$ & 0.208 \\
\hline After 3 & $34(3-2093)$ & $222.4 \pm 621$ & 0.119 \\
\hline After 4 & $16(2.6-720)$ & $82.7 \pm 212.1$ & $0.021^{*}$ \\
\hline After 5 & $10(2-213)$ & $27.4 \pm 61.9$ & $0.001^{*}$ \\
\hline After 6 & $4(0.50-54)$ & $9.2 \pm 15.2$ & $<0.001^{*}$ \\
\hline After 7 & $2.4(1-16)$ & $3.9 \pm 4.1$ & $<0.001^{*}$ \\
\hline After 8 & $2.5(1-12)$ & $3.8 \pm 3.1$ & $<0.001^{*}$ \\
\hline After 9 & $2.4(1.4-11)$ & $3.2 \pm 2.7$ & $<0.001^{*}$ \\
\hline After 10 & $2.2(1.5-7)$ & $2.8 \pm 1.6$ & $<0.001^{*}$ \\
\hline After 11 & $2.2(1-4)$ & $2.3 \pm 0.90$ & $<0.001^{*}$ \\
\hline After 12 & $2(0.40-3.5)$ & $2 \pm 0.77$ & $<0.001^{*}$ \\
\hline
\end{tabular}

*Statistically significant at $\mathrm{p} \leq 0.05$ for Friedman test for comparing between before and each other periods.

The common procedure of suction evacuation and curettage, ideally performed under ultrasound guidance, is the preferred method of evacuation of a molar pregnancy independent of uterine size if preservation of fertility is desired. It is recommended that a $12-14 \mathrm{~mm}$ suction cannula is used and that an intravenous oxytocin infusion is started at the onset of suction curettage and continued for several hours postoperatively to enhance uterine contractility. ${ }^{3}$ There is a risk of bleeding that increases with uterine size, blood for transfusion should be available when the uterus is greater than 16 weeks of gestational age. Judicious use of appropriate evacuation equipment and techniques, careful intraoperative monitoring, access to blood products and early recognition and correction of complications result in better outcome. Radiotherapy has limited role in GTD as trophoblasts are radioresistant and surgery is limited only to cases with uncontrolled vaginal bleeding and very large uterus. ${ }^{5,6}$
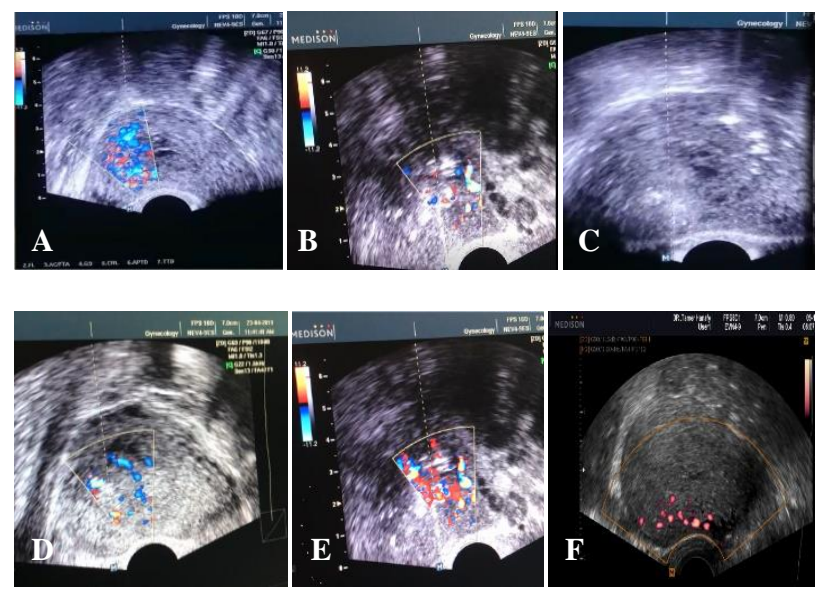

Figure 2: A) high vascularity of the local invasive mole in the myometrium by color Doppler, B) local injection of methotrexate, $C$ ) the invasive mole after local injection with the doppler off, D) after injection with doppler $E$ ) another case during injection in the post wall of the uterus and $F$ ) the doppler study of a case after 6 weeks of local injection.

In management of invasive GTD fertility sparing approach and/or minimally invasive techniques should be tried to preserve fertility as most of the cases are in the childbearing period of their lives. ${ }^{7-9}$ Patients with low risk for GTN (WHO risk score 0-4) should be treated with one of the single agent methotrexates or actinomycin D protocols. $^{5}$ Chemotherapy should be changed to the alternative single agent if there is a good response to the first agent but the hCG level plateau is above normal during treatment, or if toxicity precludes an adequate dose or frequency of treatment. ${ }^{3,10}$ If there is an inadequate response to the initial single agent, multiple agent chemotherapy should be tried. The high risk group or those with significant elevation in hCG level, development of metastasis and/or resistance to sequential single agent chemotherapy should start multiagent protocol. ${ }^{11}$ The local injection of methotrexate was tried in many case reports and was found to be a successful minimally invasive alternative for systemic multiagent chemotherapeutic therapy notably in young women with reproductive needs. ${ }^{12-14}$

The use of repeated injection of methotrexate in the invasive mole succeeded to decrease the activity and hormonal production of the mole over weeks and the high vascular pattern of the mole subsided dramatically. The local injections were very tolerable, cost effective and spare the fertility of the patients as they were not exposed to the harmful multiagent chemotherapeutic agents. The only drawback of these cases was the late referral as many unneeded dilatation and curettage procedures were done and many methotrexate injections were given. 


\section{CONCLUSION}

Treatment of the invasive trophoblastic disease during reproductive age is still a challenge for all clinicians. The local injection of methotrexate intramyometrial inside the lesion is effective alternative to multiagent chemotherapy protocols and more suitable for patients desiring pregnancy.

Funding: No funding sources Conflict of interest: None declared

Ethical approval: Not required

\section{REFERENCES}

1. Kaur B, Short D, Fisher RA, Savage PM, Seckl MJ, Sebire NJ. A typical placental site nodule (APSN) and association with malignant gestational trophoblastic disease; a clinicopathologic study of 21 cases. Int J Gynecol Pathol. 2015;34(2):152-8.

2. Berkowitz R, Ozturk M, Goldstein D, Bernstein M, Hill L, Wands JR. Human chorionic gonadotropin and free subunits' serum levels in patients with partial and complete hydatidiform moles. Obstet Gynecol. 1989;74(2):212-6.

3. Lawrie TA, Alazzam M, Tidy J, Hancock BW, Osborne R. First-line chemotherapy in low-risk gestational trophoblastic neoplasia. Cochrane Database Syst Rev. 2016;2016(6):CD007102.

4. Ngan HY, Bender H, Benedet JL, Jones H, Montruccoli GC, Pecorelli S; FIGO Committee on Gynecologic Oncology. Gestational trophoblastic neoplasia, FIGO 2000 staging and classification. Int J Gynaecol Obstet. 2003;83(Suppl 1):175-7.

5. Seckl MJ, Sebire NJ, Berkowitz RS. Gestational trophoblastic disease. Lancet. 2010;376(9742):71729.

6. Ngan HY, Kohorn EI, Cole LA, Kurman RJ, Kim SJ, Lurain JR, Seckl MJ, Sasaki S, Soper JT. Trophoblastic disease. Int J Gynaecol Obstet. 2012; 119(Suppl 2):S130-6.
7. Ashton E, Szutowska M, Shafer A, Hoffman J. Attempted conservative management of a placental site trophoblastic tumor: a case report. Conn Med. 2014;78(8):475-7.

8. Numnum TM, Kilgore LC, Conner MG, Straughn JM Jr. Fertility sparing therapy in a patient with placental site trophoblastic tumor: a case report. Gynecol Oncol. 2006;103(3):1141-3.

9. Pfeffer PE, Sebire N, Lindsay I, McIndoe A, Lim A, Seckl MJ. Fertility-sparing partial hysterectomy for placental-site trophoblastic tumour. Lancet Oncol. 2007;8(8):744-6.

10. Wang Q, Fu J, Hu L, Fang F, Xie L, Chen H, He F, $\mathrm{Wu}$ T, Lawrie TA. Prophylactic chemotherapy for hydatidiform mole to prevent gestational trophoblastic neoplasia. Cochrane Database Syst Rev. 2017;9(9):CD007289.

11. Berkowitz RS, Goldstein DP. Clinical practice. Molar pregnancy. N Engl J Med. 2009;360(16): 1639-45.

12. Su WH, Wang PH, Chang SP. Successful treatment of a persistent mole with myometrial invasion by direct injection of methotrexate. Eur J Gynaecol Oncol. 2001;22(4):283-6.

13. Alazzam M, Tidy J, Osborne R, Coleman R, Hancock BW, Lawrie TA. Chemotherapy for resistant or recurrent gestational trophoblastic neoplasia. Cochrane Database Syst Rev. 2016; 2016(1):CD008891.

14. Tsukihara S, Harada T, Terakawa N. Ultrasoundguided local injection of methotrexate to treat an invasive hydatidiform mole. J Obstet Gynaecol Res. 2004;30(3):202-4.

Cite this article as: Said TH, Elkerm Y. Repeated ultrasound guided local infiltration of methotrexate in persistent gestational trophoblastic disease with myometrial invasion: case series and review of literature. Int J Reprod Contracept Obstet Gynecol 2021;10:2045-9. 